\title{
Desde Europa del Este a los EEUU, y desde España a Chile: las raíces de mi identidad
}

From Eastern Europe to the USA, and from Spain to Chile: the roots of my identity

Brian Chernin de la Fuente brianchernin@gmail.com Universidad de Chile

\section{Resumen}

Chile

Debido a la variada ascendencia, mi hogar siempre ha sido un vivo reflejo del pluralismo cultural. Por un lado, mi papá es estadounidense, y viene de una familia judía cuyos orígenes se remontan al Imperio Ruso. Y por el otro, mi mamá es chilena y católica, y sus antepasados fueron en su mayoría españoles que arribaron a Chile a comienzos de la época colonial. Por esto, me crié en una amalgama de tradiciones e identidades, que actualmente me definen. Sin embargo, este proceso no fue fácil, pues debí ahondar en mis, hasta ese entonces, desconocidas raíces paternas. Decidí narrar en este texto mi memoria familiar, basándome en mis cuatro abuelos, en una travesía que me llevó por la historia de varios países, y que da como resultado quién soy actualmente.

PALABRAS CLAVES: memoria familiar, multiculturalidad, judíos rusos, familias chilenas, judíos neoyorquinos

\begin{abstract}
Due to the varied ascendancy, my home has always been a shelter of cultural pluralism. On the one hand, my father is an American Jew, whose origins go back to the Russian Empire. On the other hand, my mother is a Chilean Catholic, whose ancestors were mainly Spaniards who arrived to Chile in the beginning of the Colonial era. Thus, I was brought up in an amalgam of traditions and identities that nowadays define me. However, this process was not easy, for I had to investigate my paternal roots, which used to be unknown to me. I decided to narrate in this text my family memoirs, telling the stories of my four grandparents, in a journey that took me across the history of many countries, and that concludes with who I am today.
\end{abstract}


KEYWORDS: family memoir, multiculturalism, Russian Jews, Chilean families, New York Jews

Creo que sé perfectamente lo que es la multiculturalidad, y con ello, las ventajas y desventajas que conlleva. Las familias de mi padre y madre tienen antecedentes sumamente distintos, cosa de la cual me percaté recién hace unos años. Cuando uno está envuelto en ese ambiente pluralista, donde no hay unidad en el hogar en temas de rituales religiosos, hitos históricos vividos o ideologías, uno simplemente ve la realidad de manera distinta, uno cree que esa amalgama de bienes culturales constituye una sola cultura. Pero, cuando intentamos explicar ello a otros, entramos en conflictos. Muchas veces me he sentido como el típico hijo mestizo de tiempos coloniales, que no era ni español ni indígena, sino que simplemente un poco de esto y aquello.

Mi padre, Irwin Chernin Fuchsman, es judío, estadounidense, de una familia de clase media emergente que por ningún motivo quería retroceder a la pobreza. En cambio, Mariana de la Fuente Santander, mi mamá, es católica, chilena, de una familia muy acomodada, y que en su mayoría, lo fue desde tiempos coloniales.

No es fácil tratar de encajar en ambos grupos cuando no quieres perder una de las dos culturas. Ir a una sinagoga, que te traten como judío, y sepan que tu madre practica el catolicismo, muchas veces no es de agrado de los rabinos. Por otro lado, estar en constante contacto con tu familia materna, y sólo compartir ciertos rasgos, hace que te sientas enajenado respecto de los otros. Pero a pesar de todo ello, los genes son fuertes, y pude encontrar la manera de vivir ambas culturas sin que entrasen en disputa. Siempre me fue más conocida la historia por mi lado materno. Mi abuela sigue viva, e ir a su departamento es un verdadero encuentro con el pasado. Me cuenta historias y anécdotas de sus abuelos y bisabuelos, y me muestra fotos viejas e incluso un libro que escribió su padre sobre su vida. También, a pesar de que mi abuelo está muerto, mi abuela frecuentemente relata cosas de la familia de su marido que le contaron mi abuelo, sus cuñados y suegros, lo que hace que mi memoria familiar por ese lado sea sumamente copiosa. Pero siempre sentí un vacío por no ver lo mismo en el lado de mi papá. Con suerte sabía de mis abuelos, no tenía idea de dónde venían sus padres, y lo que era peor, no había muchas fuentes para sacar información a mi 
alcance. Por si fuese poco, sólo me enteré de que mi padre era judío cuando estaba en tercero básico, y nos hicieron elegir un curso de religión en el colegio. Fue en esas clases donde aprendí mucho de mi herencia por lado paterno, y comencé a descubrirla. Aun considerando eso, no sentía que aquellas cosas que aprendía me pertenecieran, por la falta de conocimiento que tenía de la historia de mis antepasados judíos. Pero un día ya no aguante más, y decidí averiguar de aquella ascendencia. Había tantas preguntas: ¿de dónde venían? ¿Quiénes eran? ¿Qué cosas les había tocado vivir? Por suerte pude dar con la gran mayoría de estas inquietudes, y noté que a veces hay que ir más allá de tu familia cercana para solventar estas dudas. La familia es un gran árbol que tiene muchos ramales, y finalmente, gente que jamás has visto, tiene vínculo con antepasados tuyos, y te puede dar hasta más información de la que tu familia cercana podría haberte dado. Ya conociendo bien ambas partes de mi ascendencia, he podido sentirme tranquilo. Tengo hermosos legados y herencias culturales por ambos lados, y siento que mi identidad está compuesta de ese sincretismo. A pesar de practicar la fe judía, tengo tan internalizada la Navidad, y tradiciones como poner el árbol y la cena familiar, que no podría dejar de hacerlo. Asimismo, toda la historia que me ata a Chile procede del lado de mi mamá. Pero, ahora que he podido establecer fuertes vínculos de identificación con mi ascendencia paterna, también hago parte de mi vida cosas que heredé de ese lado. Por ejemplo, prendo las velas de Janucá en una janukiá que fue regalada a mis abuelos a mediados de la década del cincuenta, y a veces voy a la sinagoga con la kipá que pertenecía a mi abuelo. Toda esta mezcla conforma quién soy, y si me faltara cualquiera de las dos partes, me sentiría incompleto.

\section{Grandpa Julie}

Julius Stanley Roy Chernin Bolotin, mi abuelo paterno, nació el 10 de septiembre de 1918 en Morristown, NJ, USA. Era el primogénito del matrimonio conformado por Anshel (Ike) Chernin Volinsky, inmigrante bielorruso, y Chaya (Clara) Bolotin Narinsky, inmigrante ucraniana. En aquella época los dos lugares de nacimiento de sus padres, a pesar de constituir regiones distintas, pertenecían a la misma nación, y ésta era el Imperio Ruso. Venido a este mundo tan sólo 6 años después del arribo de sus padres a los Estados Unidos, mi abuelo se crio en un hogar en constante conflicto entre la asimilación a la cultura estadounidense, y la preservación de sus raíces judíorusas. La lengua materna de mi abuelo, para mi sorpresa, fue el ruso. Digo que me sorprendió, 
porque conocí a mi abuelo, y jamás pensé que hubiese hablado ruso. Su inglés era perfecto, como el de todo norteamericano, y por si fuese poco, mi padre jamás había mencionado algo al respecto. Este hecho vino a mi conocimiento luego de que el hermano de mi padre me contara una historia. Cuando Julius entró al colegio, a mediados de la década de 1920, volvió a casa llorando. Mi bisabuelo Anshel le preguntó qué ocurría, a lo que mi abuelo respondió en ruso que no entendía nada de lo que sus compañeros hablaban ni de lo que enseñaban en clases. Además, su falta de léxico en inglés lo hacía ser causal de burlas entre sus compañeros, pues claramente no era uno de ellos, claramente no era norteamericano. Al escuchar a su hijo llorar y pronunciar esas palabras, Anshel, con su característico autoritarismo y penetrante voz, decretó que en su casa no se volvía a hablar ruso, y que sólo sería el inglés la lengua de la familia. Este hecho ilustra perfectamente la dicotomía presente en el hogar. Anshel, por un lado, quería asimilarse a la cultura norteamericana, jugar baseball, celebrar el 4 de julio y ser uno más, dejando de lado sus raíces rusas e incluso judías. Chaya, por el otro lado, estaba consciente de que el mundo cambiaba y ella también debía hacerlo, pero que eso no implicaba dejar de lado todo lo que eran, sus raíces. Como el mundo era machista, y mi bisabuelo destacaba por ello, Chaya debía acatar su parecer. A pesar de ello, mi bisabuela se salía con la suya cuando podía. A modo de ejemplo está el bar mitzvá de mi abuelo. Anshel renegaba de su pasado judío. El haberse criado en un hogar ortodoxo lo había colmado, y esta nueva vida en los Estados Unidos, lejos de sus padres y del shtetl de dónde provenía, era la perfecta instancia para ser quién quisiese ser. Era tal la falta de apego a su cultura, que para fiestas importantísimas como Yom Kippur, mi bisabuelo obligaba a su mujer a cocinarle. Ella por vergüenza, pues vivían en un barrio judío y además era sumamente creyente, cerraba todas las cortinas del hogar para que nadie viese. Volviendo al tema del bar mitzvá, mi bisabuelo no quería que su hijo tuviese esta ceremonia. Para todo varón judío, este momento es crucial, pues marca la transición de la niñez a la adultez. Mi bisabuela, por supuesto, encontraba esto terrible, pero al ser su marido el que mandaba, no podía optar por pelear con él. No obstante ello, se salió con la suya de una manera sumamente ingeniosa. Le pidió a su cuñado, el hermano mayor de mi bisabuelo, que saliese con él un sábado por el día. Y mientras ello ocurría, ella acudió con su hijo a la sinagoga donde finalmente tuvo la tan anhelada ceremonia. 
La situación económica de la familia Chernin Bolotin fue mejorando. Mi bisabuelo era sastre y había desempeñado dicho oficio desde que era joven en Bielorrusia. Mi bisabuela era dueña de casa, y como tal, se dedicaba al cuidado de sus hijos y a las tareas del hogar. Cuando mi abuelo y su hermana Lillian eran pequeños, vivían en un departamento en Brooklyn. Lillian, que aún sigue viva, me cuenta que tenían una vida sacrificada. Su departamento no tenía baño, había sólo uno en todo el piso, y tampoco tenía calefacción. Puede que para alguien en Chile, la calefacción sea un bien suntuario, pero en los años veinte en Estados Unidos, era considerado algo básico. Por esto, los Chernin Bolotin pasaban todo el invierno en la cocina junto al horno para no congelarse, e igualmente, a veces se bañaban en el lavaplatos, secándose con la única toalla que poseían.

A medida que pasaban los años, las cosas iban mejorando. Los dos hijos terminaron el colegio y enseguida comenzaron a trabajar. Mi abuelo se graduó del Alexander Hamilton High School, ubicado en la zona de Bushwick en Brooklyn. En el censo federal de los Estados Unidos de 1940, se observa que todos, salvo mi bisabuela, trabajaban. Aquí se esboza nuevamente el machismo encarnado por mi bisabuelo, pues jamás dejó que Chaya entrara al mundo laboral. Esto sólo ocurriría después del 10 de mayo de 1950, cuando ella ya hubiese enviudado, tras perder a su marido a causa de un terrible cáncer al colon. Anshel tenía tan sólo 57 años, pero la enfermedad terminó abruptamente con él. Según Lillian, en sus últimos meses de vida, olvidó el inglés y el yiddish, y sólo era capaz de comunicarse en ruso. Por lo mismo, Chaya era la única que podía desarrollar una buena plática con él. Mi abuelo, quién había sido criado bajo la lengua rusa, había perdido toda fluidez y sólo preservaba lo básico de ésta. En esa década anterior a su muerte, los años cuarenta, muchas cosas habían acontecido. En primer lugar, mi abuelo Julius había sido enviado a Europa a causa de la Segunda Guerra Mundial. Estuvo varios años allá, donde realmente se salvó por milagro. Nunca tuve la oportunidad de hablar de estos temas con él, aunque según mis familiares, era sumamente callado respecto a ese tema. Lo único que se sabe, es que debió liberar campos de concentración en Alemania, entre ellos el de Buchenwald, y que, gracias a una neumonía que padeció a fines de 1944, se salvó de combatir en la Batalla de las Ardenas, donde prácticamente toda su unidad pereció. Hay varias historias familiares que se relacionan a la guerra. En primer lugar, me han contado que mientras mi abuelo combatía, Anshel había tenido una trágica pesadilla. Soñó que llegaba de Europa el ataúd de su hijo muerto, y que 
le hacía un traje a medida para así poder enterrarlo. Esto le fue contado a mi abuelo años después, cuando consideró enlistarse nuevamente en el ejército, pues había adorado la disciplina que en él había. Luego, se dice que leyendo un diario en Italia, mi abuelo vio una foto de un general de la batalla de Stalingrado, que se parecía muchísimo a su padre. Supuestamente, la recortó y se la mandó, a lo que él respondió que era un primo hermano. Insisto que no sé cuán fidedignas sean estas narraciones, pero son parte de lo que me han transmitido oralmente mis parientes. Además de la guerra, en la década de 1940, se casaron los dos hijos de Anshel y Chaya. Mi abuelo lo hizo el 21 de septiembre de 1947, con mi abuela Sara Fuchsman Treger, luego de haber estudiado gratis contabilidad, en retribución a sus servicios militares.

$\mathrm{Si}$ ahondamos en los orígenes de esta familia, podemos llegar algunas generaciones más arriba. Mi bisabuelo Anshel, como mencioné anteriormente, era bielorruso. Él nació, según documentos que ostento, el 12 de julio de 1891, en el shtetl de Loyev, ubicado en la región de Minsk, en la ribera del río Dniéper. Actualmente, este curso de agua es la frontera entre Bielorrusia y Ucrania, y en esas épocas, lo era entre distintas provincias. Los padres de Anshel eran Moshe Chernin, un hombre que presentaba el mismo patrón dictatorial y machista de su hijo, y Michla Volinsky, una mujer bastante triste y menospreciada. Este matrimonio tuvo, al menos nueve hijos. De ellos, cinco emigraron a los Estados Unidos, y cuatro permanecieron en la URSS. Qué ocurrió con éstos es algo que hasta el día de hoy desconozco, pero leyendo la historia de esa zona, lo más probable es que hayan muerto ahí, en el Holocausto, o bien bajo el régimen estalinista, que fue sumamente adverso hacia los judíos. Moshe era herrero, y según mi abuelo, pertenecía a la clase de pequeños propietarios rurales, o kulaks. Tenía negocios, entre ellos el de herrería que era familiar, y por lo mismo, para la realidad judío-rusa, era una familia adinerada. Según la lista de votantes de la DUMA en Bielorrusia de 1906, mi tatarabuelo poseía una propiedad avaluada en 250 rublos, lo que considerando el valor relativo de las otras, era bastante. Tan importante era el que fuese propietario, que le daba derecho a votar, atribución de suma exclusividad, pues había muchos requisitos para esto, y más aún si se era judío. El matrimonio entre Moshe y Michla, como era la tradición ortodoxa en la época, fue arreglado. De sus orígenes, aunque es poco, puedo rescatar lo siguiente: Moshe nació en la región de Minsk en Bielorrusia, y el nombre de su padre era Abraham Chernin. Este señor es una verdadera leyenda en la familia, pues se dice que 
vivió cerca de 90 años, y que se casó tres veces, teniendo decenas de hijos. Poseo una foto de él junto a su mujer. Ambos tienen aspecto de campesinos, y él particularmente, de persona religiosa, con una pronunciada barba blanca. Michla, por su lado, nació en la misma zona. De sus papás, aunque desconozco sus nombres, tengo una foto. Se ven bastante cultos y pudientes si se comparan con los padres de Moshe. Tienen igualmente una apariencia religiosa, pero sus atuendos son mucho más sofisticados, y el padre lleva un libro en la mano.

El machismo de Moshe Chernin era tan exacerbado, que rutinariamente decía a su esposa y cuatro hijas que las mujeres sólo servían para labores domésticas y procrear, y por supuesto, complacer al marido a toda costa. Esto era precisamente lo que hacía Michla, quien según sus nietas mayores, era vista y tratada como sirvienta. Al mirar los dos retratos que conservo de ella, me es evidente que no era una mujer feliz. Aunque tienen años de diferencia, en ambas fotos su cara evoca una honda tristeza y congoja, como si estuviese decepcionada de la vida que le tocó. Sus hijas, sin embargo, no siguieron con la actitud sumisa de su madre. De hecho, Sara, una de las que emigró a los Estados Unidos, se tomó una foto desnuda y se la envió por correo a su padre, sólo con el fin de hacerlo rabiar. Durante los inviernos, Michla se sentaba con sus nietas mayores en la estufa o gruba que tenían en la antesala, y pasaba la noche entera allí para que no sintieran frío. Las quería mucho, y ellas la conocían como babushka, que en ruso significa abuela. Moshe, por el otro lado, era conocido como zeyde, abuelo en yiddish. Para él la educación era importante, y por lo mismo, se preocupó de que sus hijos asistieran algunos años a un gymnasium, o escuela secundaria, en Bielorrusia. Además, tenía tutor privado para una de sus nietas, antes de que con la llegada de la Revolución Bolchevique y la Guerra con Polonia de 1919, las cosas se complicaran.

La persecución judía en forma de pogromos, o simplemente agresiones, era algo que se respiraba en el día a día. No era raro que muchos judíos tuviesen miedo de sus pares cristianos. En ese sentido, la educación les jugó a favor a mis antepasados, pues al haber aprendido ruso, podían pasar inadvertidos en las temidas redadas que hacía el ejército zarista cada cierto tiempo. Al estar el shtetl de Loyev ubicado en la ribera del río Dniéper, los militares disponían gente al azar en el muelle de la localidad. Uno a uno, les hacían pronunciar palabras en ruso, y si éstas sonaban con acento yiddish, se procedía a dispararles y caían directamente muertos al río. Sé que suena algo 
extremo e increíble, pero todo esto es cierto. Mi bisabuelo y sus familiares encararon la muerte un sinnúmero de veces, pero tal como lo demuestra la historia judía, esto no pudo extinguirlos. Otras de las persecuciones narradas por mis parientes, ocurría en los barcos que transitaban por el Dniéper. Dentro del Imperio Ruso, eran las capitales de provincia las ciudades que contaban con todos los servicios públicos y administrativos. Por lo mismo, era necesario acudir a éstas cada cierto tiempo, normalmente navegando por el río. Varias veces, se subían grupos antisemitas a las embarcaciones que transitaban por ellos, y asesinaban a los judíos que viajaban en dichos navíos, sin resquemor alguno. En una ocasión, el marido de una hermana de mi bisabuelo, estaba volviendo de Kiev en buque. Miembros de un conocido grupo antisemita aparecieron y comenzaron a matar judíos. Éste, para salvarse, decidió saltar por la borda y nadar a la orilla más cercana. Por suerte era verano, y el agua no estaba tan fría, como habría ocurrido en otras estaciones del año. La frecuencia de acontecimientos como éste, hacían nacer un profundo miedo entre la judería rusa. Aunque vivían en un asentamiento muy pequeño, cada vez que alguien tocaba la puerta de la casa, la familia devenía asustada, temiendo que pudiese tratarse de otro pogromo más.

En relación a los orígenes de mi bisabuela Chaya, o "Chaika" como la conocían todos, debo aclarar que hay mucho misterio. Con ardua investigación he podido averiguar que nació el 5 de julio de 1894, en la localidad de Romny, ubicada en la provincia de Poltava, en Ucrania. Sus padres eran Mendel Bolotin, un campesino sumamente pobre, y Liba Narinsky, una mujer kosher. También, me cuenta mi tía abuela Lillian, que una de las abuelas de Chaya, no sabe bien cuál, se llamaba Gitel. Ambos progenitores nacieron en el Imperio Ruso, pero desconozco más detalles que ello. Los Bolotin Narinsky eran, según mi familia, al menos nueve hermanos, destacando por sobre todo la pobreza en que vivían. Lamentablemente esto es todo lo que sé, y se debe mayormente a lo discreta que era mi bisabuela en términos de su vida en el viejo país. Hablando con su hija, sólo pude saber que había llegado a los 18 años, que viajaba sola, que había conocido a una mujer en el barco que se convertiría en su mejor amiga de por vida, y que provenía de la Poltavskaya Guberniya, nombre ruso de la región que mencioné anteriormente. Al encontrarse en el corazón de la zona tradicional del Imperio Ruso, el idioma hablado por esta familia era el mismo, cosa que no se repetía en todos los judíos de la nación, pues también estaba 
el mucho más popular yiddish. Este pasado tan secreto debe tener una explicación, pero aún no logro encontrarla. Illene, la nieta mayor de mi bisabuela, me cuenta que todos los sábados Chaya miraba por la ventana del departamento en que vivían y lloraba. Ella nunca se atrevió a preguntar a qué se debían tantas lágrimas y sollozos, pero todos coincidimos en que debió tratarse de algo sobre su familia. Liba, la madre de Chaya, falleció antes de 1920, y Mendel, el padre, lo hizo en el Holocausto. Sabemos que gran parte de los hermanos de mi bisabuela pereció de la misma manera, pero insisto, no era un tema que ella tocara. Tras finalizar la guerra, su querida amiga viajó a la URSS para ver cómo estaba todo. Mi bisabuela le entregó su vieja dirección en Romny, y le pidió que averiguara sobre la familia, pues habían perdido todo contacto. Al volver, lo descrito por ella fue trágico. El pueblo había sido destruido, y ya no quedaba nada en la calle donde solían vivir. Nunca he podido explicarme cómo es posible que una niñita de 18 años, sin conocer el idioma y sin dinero, haya decidido emprender tal travesía para no volver a ver a sus cercanos jamás. Tiene que haber habido una razón fuerte y una gran desesperación.

Para ser aceptado en los Estados Unidos, era requisito tener alguien que auspiciara al inmigrante, con lo que se aseguraba que éste no fuese a convertirse en una carga para el Estado. Mi bisabuela, sorprendentemente, fue auspiciada por un amigo de amigos de la familia, al que posteriormente se conocería como "Uncle Harry". En un comienzo pensé que podía haber algún enfrentamiento con la familia, pero esta tesis me fue refutada cuando, al conversar con su hija y nieta, me contaban que siempre decía que su madre era tan gentil y buena persona. El segundo punto que se contrapone a mi idea inicial, es que nombró a todos sus descendientes en honor a alguien de su familia. Entonces, resulta evidente que había un cariño y preocupación por parte de mi bisabuela, que pretendían preservar la memoria de sus antepasados y raíces. Por el contrario, mi bisabuelo Anshel, aunque era cercano a su familia, no nombró a un solo descendiente en honor a alguien de su lado.

Chaya se embarcó en el puerto de Libau, ubicado dentro del Imperio Ruso, a fines de octubre de 1912, y arribó a Nueva York el 11 de noviembre del mismo año. 


\section{Grandma Sidne}

Mi abuela paterna, Sara Fuchsman Treger, era la tercera y última hija del matrimonio conformado por los moldavos Itzhak Fuchsman Grosskopf y Nechama Treger Wasserman. Sus padres, si bien habían nacido en el Imperio Ruso, tenían una variada ascendencia. Esto se debe a que la zona de Besarabia en Moldavia recién fue anexionada a dicho imperio en 1812. Antes de esto estuvo en manos de los turcos, a lo que se suma la ola de inmigrantes austriacos que provino de la región de Galitzia cuando estas tierras pasaron a soberanía rusa, además de la considerable cantidad de colonos alemanes que se asentaron en la zona. Con todo esto, es posible entender por qué los padres de mi abuela, a pesar de haber nacido en Rusia, hablaban sólo yiddish, tenían apellidos de origen germano y características culturales distintas a los judíos que vivían en la parte más céntrica del Imperio. Incluso, esta mezcla se veía en la arquitectura. Lamentablemente la zona de Besarabia fue devastada tras la ocupación Nazi en la Segunda Guerra Mundial, siendo uno de los pocos edificios que sobrevivió la catedral de la ciudad de Kishinev. Antes de la destrucción, si uno ve fotos antiguas, es posible darse cuenta de cómo las construcciones tenían una influencia rusa y también turca. La principal sinagoga, tenía ciertos rasgos que la hacían parecer mezquita, así como también, las características cúpulas rusas con forma de cebolla.

El abuelo paterno de mi abuela, Mendel Yaakov Fuchsman, nació en Kishinev (la capital de la entonces región de Besarabia y actual Moldavia) en 1866. Su abuelo paterno, del mismo nombre, había emigrado a la ciudad desde una de las granjas comuneras que proliferaban en el Imperio Ruso en la época. Tenía un cargo en dicha localidad, desiatsky, que investigando supe que era el oficial de menor rango en dichas granjas. Por razones que desconozco, este señor emigró a Kishinev y casó con una mujer de nombre Henia, con quien tuvo en 1845, a Itzhak Fuchsman (el padre del abuelo paterno de mi abuela). Gracias a esto pude saber que tres generaciones de Fuchsman fueron las que nacieron en Kishinev. Conozco poco sobre Itzhak. Se casó con una mujer de nombre Chava-Yentl, de quien poseo una foto. No estoy al tanto de su apellido, pero sí de que su padre se llamaba Yaakov Shmuel. Es muy factible que ella haya sido de ascendencia sefaradí-rumana, puesto que tiene rasgos y un colorido bastante distintos a los askenazí convencionales. El abuelo paterno de mi abuela fue el primer hijo de este matrimonio, y recibió los nombres de sus dos abuelos, Mendel y Yaakov. Mi tatarabuelo Mendel pertenecía a la clase 
media de Kishinev. Para la realidad de los judíos allá, tenía una situación económica bastante buena. Evidencia de ello, es que estaba inscrito en la lista de votantes de la DUMA de Besarabia, y la razón que se señala es que arrendaba una propiedad y pagaba los impuestos correspondientes. Desconozco cuál era la ocupación de Mendel, pero infiero que era comerciante, o tenía algún tipo de negocio. El 4 de abril de 1889, se casó con mi tatarabuela Ester Grosskopf. Ella es un ejemplo de la enorme cantidad de inmigrantes que había en la zona, pues había nacido en la villa de Siedliszcze, en la región de Lublin, en Polonia en 1868. Mi tatarabuela Ester era hija de Markus Grosskopf, cuyo nombre hebreo era Mordechai, quien muy probablemente nació en Austria o Alemania. El hijo mayor del matrimonio de Mendel y Ester fue mi bisabuelo Itzhak Fuchsman Grosskopf, el que nació el 10 de marzo de 1891 en Kishinev. Tuvieron varios otros hijos y se desempeñaron en el área de la música. Una tía me contó que eran concertistas y que viajaban a países como Italia, Francia o Rumania para tocar. Hay varias fotos de los hermanos, donde se los ve tocando el violín, el acordeón o el piano. También, encontré un documento de personas perecidas en el Holocausto en Rumania (tras la Primera Guerra Mundial, Besarabia pasó a ser parte de Rumania), que trataba sobre uno de los hermanos de mi bisabuelo, Baruch Fuchsman, cuya profesión era la de músico. Antes de hablar de la familia en Estados Unidos, hablaré de los antecedentes de la madre de mi abuela, Nechama Treger Wasserman. Los abuelos paternos de mi bisabuela eran Leib Treger y Nechama, quienes tuvieron en Kishinev al menos tres hijos: David, Wolf y Moshe Gershon, siendo este último mi tatarabuelo. Moshe Treger era obrero. Se desempeñó, al menos un tiempo, como tal en una fábrica de vagones. No era un hombre muy alto, de $1.65 \mathrm{~m}$. de altura aproximadamente, y tenía ojos y pelo café. En las diversas fotos que tengo de él, aparece con una pronunciada barba. En 1890, aproximadamente a sus 28 años de edad, se casó con Machla Wasserman. Ella era hija de Abraham Hersh Wasserman y Rivka Cohen, y tenía otras dos hermanas, Ester y Rachel. Ambas emigraron a los Estados Unidos. Ester acogió a mi bisabuela cuando recién venía llegando a Nueva York, y vivieron juntas hasta que murió en 1926. Rachel (alias "la Mimi"), por su parte, se casó varias veces, pero no dejó descendencia. Lo increíble es que incluso mi padre la conoció. Fue la única persona de la generación de sus bisabuelos que alcanzó a ver, y hasta mi investigación, él no sabía que "la Mimi” era nada más ni nada menos que su tía bisabuela. Rachel falleció en 1957, a la edad de 87 años, en un hogar de ancianos ubicado en Brooklyn, NY. Volviendo a mi tatarabuela Machla, ella 
nació en Kishinev en 1870. Su vida fue bastante corta, pues falleció el 12 de diciembre de 1902, a la edad de 32 años, a causa de una peritonitis. La defunción se produjo en el Hospital Judío de la misma ciudad, dejando a tres hijos pequeños. La mayor de ellos fue Nechama, mi bisabuela, que nació en 1894 y de quien hablaré después. En segundo lugar, vino Pesia, la que emigró junto a mi bisabuela a los Estados Unidos. Finalmente, nació el único hombre, Leib, quien falleció a la temprana de edad de 17 años, por una feroz tuberculosis.

La vida de mi bisabuela Nechama en Kishinev fue bastante difícil. Perdió a su madre a sus 8 años, debió trabajar cosiendo y bordando para ganar dinero y así colaborar con los gastos del hogar, y asimismo, vivió muchas persecuciones antisemitas. De hecho, el 6 y 7 de abril de 1903, aconteció el pogromo de Kishinev, el que es considerado el más sangriento en la historia de la judería rusa. Mi bisabuela ya era huérfana de madre, y su padre había contraído matrimonio en marzo del mismo año con Sara Kiskaman Kitces, otra viuda, que tenía una hija, Ester Iosefovici Kiskaman. 1903 había estado caracterizado por un creciente antisemitismo provocado por nacionalistas, y en Semana Santa, se propagó el rumor de que un pequeño niño cristiano, Mikhail Rybachenko, había sido asesinado por judíos, para utilizar su sangre a modo de ritual. Periódicos como el Bessarabetz o Svet, que contaban con editores bastante antisemitas, fueron los artífices de esta mentira, que culminó en un descontento por parte de la comunidad cristiana de la zona, asesinando 49 judíos, hiriendo a más de 500, y saqueando y destruyendo miles de hogares y negocios, todo en la ciudad de Kishinev. Por lo que me contó esta tía, la casa de mi bisabuela y su familia fue quemada, y para evitar confrontaciones, huyeron al Hospital Judío, donde una cantidad considerable de la población hebrea buscó cobijo. El hogar de los Treger fue quemado en reiteradas ocasiones, incluso después de que los rusos habían perdido la soberanía de Besarabia, tras finalizar la Primera Guerra Mundial. Fuera de todo lo malo, mi bisabuela sí tenía ciertas alegrías, como lo fue mi bisabuelo. Ellos, como mencioné previamente, residían en la misma ciudad, y ya eran novios antes de emigrar. Muchos los denominaban "tórtolos", pero claro estaba que no podrían lograr ser felices en un ambiente tan hostil como era el cual en que se encontraban.

El 17 de septiembre de 1913, mi bisabuela Nechama, junto a su hermana Pesia, se embarcaron en el puerto de Southampton en Inglaterra, para emprender rumbo a los Estados Unidos. La idea 
había sido de su padre, pues la situación se iba complicando cada vez más para los judíos, y no parecía haber vuelta atrás. En un inicio, la vida para los judíos de Besarabia tenía muchos beneficios, tales como la exención de ciertos impuestos, y la posibilidad de ser pequeños propietarios, lo que no ocurría en el resto de las provincias. Este trato especial se debía a que la recién anexionada región necesitaba ser poblada, y había quedado rodeada por la Zona de Asentamiento Judía, por lo que atraerlos era necesario. No obstante ello, luego del asesinato del Zar Alejandro II en 1881, las cosas en toda Rusia comenzaron a empeorar para ellos, pues se les acusaba de ser los homicidas, y Besarabia no fue la excepción. La travesía a bordo del barco "Oceanic", demoró 7 días. Allá tenían a su tía Ester Wasserman Cohen, hermana de su difunta madre, como también a sus descendientes. Llegaron al Lower East Side de Nueva York, que se convirtió en el epicentro de la judería askenazí-rusa en la época. Las condiciones de vida eran deplorables, pues había mucho hacinamiento y falta de salubridad, y la desesperación por conseguir dinero y salir de allí, no ayudaba en absoluto. No debió pasar mucho tiempo para que mi bisabuelo decidiera que iría en busca de su amor al nuevo continente. El 7 de febrero de 1914, abordó en Rotterdam el barco "Nieu Amsterdam” y arribó el día 19 del mismo mes. La familia de mi bisabuelo se mostraba bastante recelosa y reticente a la idea de que él viajara. A sus 22 años ya había tenido varios problemas de salud, y consideraban que realizar tal travesía podía atentar incluso contra su vida. Finalmente, el amor lo pudo todo y decidió hacer caso omiso de estas advertencias.

Una vez en los Estados Unidos, Nechama pasó a ser Anna, Pesia era Bessie, e Itzhak era Isidore. Años después, mis bisabuelos contrajeron matrimonio, y tuvieron a sus dos hijos mayores. La primera fue Mollie, en honor a su abuela materna Machla, y el segundo Max. Nacieron en 1917 y 1918 respectivamente, ambos en la ciudad de Nueva York. Mi bisabuelo trabajó en una tienda de bicicletas, y mi bisabuela se dedicaba a trabajar en la casa, para así ganar dinero y poder salir del Lower East Side. En aquel barrio, residían en el número 64 de la calle Canal, en la intersección de dicha arteria con la calle Allen. En 2011 tuve la suerte de poder ir a Nueva York y pasé por esa esquina. Se encuentra en la mitad del ajetreado Barrio Chino, y el edificio donde vivían fue demolido para dar paso a la ampliación de la calle Allen. Es interesante cómo en Nueva York, dada la gran cantidad de inmigrantes, hay barrios que fueron colonizados por cierto grupo, y 
pasados los años, fueron abandonados por éstos para dar paso a otro grupo de inmigrantes. Tal es el caso de este sector, que a pesar de contar con casi una totalidad de habitantes chinos en la actualidad, guarda muchos vestigios de su pasado judío. Por ejemplo, se pueden ver viejos letreros en yiddish en las construcciones, o bien, algunos murales que recuerdan al movimiento obrero judío de principios del siglo XX.

A finales de 1920, llegó a Nueva York mi tatarabuelo, Moshe Treger, junto a su hijastra, Ester. Vivieron junto a mi familia en el departamento de la calle Canal. Al respecto, poseo un correo electrónico donde mi tía abuela Mollie relata sus recuerdos de infancia mientras convivía con su abuelo. Ella dice que habitaban en un departamento de dos piezas, y eran siete personas: ella, su hermano Max, sus padres, su tía Pesia, el abuelo Moshe, y la hermanastra de su madre, Ester. Mollie y Max dormían en unas sillas, para dejar las camas a la gente mayor. Moshe Treger, a pesar de las insistencias de su familia, no quiso quedarse en los Estados Unidos. Trabajó un tiempo como obrero en una fábrica de colchones, ahorró dinero suficiente para comprar una casa y volvió a Kishinev. Me cuesta entender la decisión de mi tatarabuelo, pues las cosas para los judíos en su ciudad natal no podían estar peor. De hecho, una de las razones por las que viajó, fue que su casa en Besarabia había sido quemada nuevamente en otro terrible pogromo. A pesar de que el panorama parecía sugerir que lo mejor era mudarse al nuevo continente, sin mencionar que sus hijas y nietos vivían allí, mi tatarabuelo optó por volver a Kishinev. La razón de ello fue que, bajo su criterio, los Estados Unidos no eran lo suficientemente religiosos. El ver que en el nuevo continente la gente no respetaba el kashrut, no iba rutinariamente a la sinagoga, e incluso, se asimilaba a la nueva cultura optando en algunos casos por el matrimonio con otros credos, pudo más que la libertad y seguridad que le traían esta nueva nación.

El 23 de septiembre de 1923 nace mi abuela, Sara Sidne Fuchsman Treger. Al nacer su nombre era sólo Sara, pero por razones que mencionaré adelante, agregó el nombre Sidne, e incluso, después invirtió el orden para que Sara quedara como el segundo. Mi abuela nació cuando su familia llevaba 10 años en Estados Unidos, y ya estaba algo más asentada. Al año siguiente de que llegara a este mundo, se mudaron a la zona de Bushwick en Brooklyn. Tristemente, el 7 de febrero de 1925, el padre de mi abuela, Itzhak Fuchsman, falleció. Se encontraba camino a casa cuando de repente, su corazón no dio más, y cayó muerto en la calle. Esto fue una verdadera 
tragedia para la familia. Mi bisabuela tenía entonces 30 años, y tres hijos pequeños a quienes criar y alimentar.

La vida sin su marido, le trajo nuevos desafíos a mi bisabuela. Por suerte, contaba con algo de apoyo económico de sus tías, lo que le ayudaba a pagar el arriendo. Mi abuela, y sus dos hermanos, asistieron al Bushwick High School, que se encontraba cerca de su departamento. Para ayudar con las cosas del hogar, la hermana mayor de mi abuela, Mollie, decidió salirse del colegio en primer año de secundaria. Mi abuela y su otro hermano, Max, terminaron su educación, pero sólo mi abuela estudiaría algo después. Luego de haber terminado el colegio, mi abuela decidió entrar en la Armada, en lo que se denomina WAVE (Women accepted for volunteer emergency service). Ella nunca estuvo en Europa, pero sí ayudó desde Georgia, en los Estados Unidos. El estar en la Armada le abrió el mundo. Su madre era muy sobreprotectora, a tal punto, que cuando sus hijas llevaban novios a casa, no les quitaba la vista de encima. Mi abuela era además una mujer muy atractiva. Medía 1.65, era de piel muy blanca, tenía los ojos celestes grisáceos, y el pelo castaño oscuro y ondulado. Antes de entrar a la Armada, decidió cambiar su nombre a Sidne Sara. Para no deshonrar la elección de sus padres, atribuyó dicho cambio a la discriminación que sufría por tener un nombre de pila tan judío. No considero muy creíble esa justificación, pues su nombre es utilizado por mucha gente que no necesariamente es judía. Además, mi tío Russell me contó que odiaba que le dijeran Sara.

Gracias a su servicio en la Armada de los Estados Unidos, a mi abuela le fue concedida la posibilidad de estudiar contabilidad, cursando distintos asignaturas en distintas universidades. Ésta fue una de las principales razones por las cuales pudo surgir, y tener una vida de clase media consolidada en su adultez junto a mi abuelo.

\section{Tata}

Mi tata fue el primero de mis abuelos en morir. Su hora llegó tan sólo 7 meses después de que yo llegara a este mundo. A pesar de ello, por la cercana relación que tengo con mi abuela, mis tíos y por el hecho de que mi madre siempre habla de él, es como si siguiese presente entre nosotros. José Víctor Sergio de la Fuente Illanes, que siempre fue conocido sólo por el nombre de Sergio, nació el 23 de diciembre de 1922 en Linares. Fue el primogénito del matrimonio conformado por 
José María de la Fuente de la Fuente, conocido como el abuelo Pepe, y María Olga Illanes Guerrero, conocida como la abuela Olga.

El papá de mi abuelo venía de una familia tradicional del Maule. Nació a comienzos de abril de 1892, en el fundo San Ramón, en Yerbas Buenas. Sus antepasados habían residido en la zona desde el siglo XVII y habían adquirido varias tierras por ser Realistas en la época colonial. Estos terrenos estaban desperdigados en gran parte de la zona sur del Maule, encontrándose en localidades como Curanipe, Linares, Chanco, Cauquenes, Yerbas Buenas, Huerta del Maule, y algunas casas en la ciudad de Talca. Por lo mismo, para no perder los vastos latifundios que tenían, su familia era sumamente endogámica. Los papás de mi bisabuelo eran primos en algún grado, y sus abuelos, también lo eran. Ninguno de ellos había estudiado, y quizás por eso era un sueño para mi bisabuelo el ir a la universidad. Esto lo sé, ya que en el testamento de su madre, doña Rosa de la Fuente Ciudad, aparece una disposición que señala que le dejará dinero a su hijo José María, para que concrete su sueño de ser profesional. Partió a los dieciséis años a Santiago, y vivió en una pensión. Su juventud fue bien solitaria, dado que había quedado huérfano de su padre, José María de la Fuente Vega, poco después de nacer, y su madre murió cuando tenía 25 años. Por si fuera poco, era mucho menor que el resto de sus hermanos, lo que hacía que la relación con ellos no fuera tan cercana y así, tuviese que enfrentar la vida con seriedad y responsabilidad. De hecho, todos mis parientes parecen estar de acuerdo en que las cosas que caracterizaban a mi bisabuelo eran la seriedad con que se tomaba la vida, ser sumamente dedicado y orientado a su familia, y ser totalmente adverso al riesgo. Lo increíble es que varias de estas cosas las veo en mi mamá, y ella convivió poco con su abuelo. Tras conseguir su título de médico, se casó con mi bisabuela a fines de 1921 en Linares. El abuelo Pepe rompía con todos los esquemas de su familia, ya que era primera generación en que no contraían matrimonio con alguien que fuese pariente, y además, ingresó al Partido Radical, dejando los conservadurismos de lado. Mi bisabuela Olga vivió mucho, de hecho la alcancé a conocer. Nació en mayo de 1897 y falleció a los 103 años a fines de octubre de 2000, viviendo en tres siglos. Ella también era de Linares, pero sus padres no. Habían llegado a dicha localidad en 1891, escapando de Santiago, pues eran balmacedistas. Su papá también era médico, y fue el único abuelo que mi Tata conoció. Su nombre era Víctor Luis Illanes Schedler, y según mi abuelo, lo quería tanto, que lo dejaba 
caminar por encima de la mesa de comedor de su casa en la plaza de Linares. Lamentablemente fue poco lo que duró esa relación, puesto que Víctor Luis falleció en 1929, cuando mi abuelo tenía 6 años y medio. En una vieja postal que encontré, había una foto de mi Tata cuando era guagua, y estaba dirigida a Víctor Luis. Ahí aprendí que este abuelo era además el padrino de mi abuelo. Sus antepasados venían de La Serena, y es una de las líneas de profesionales más antiguas que ostento en mi genealogía. Mi tatarabuelo se tituló de médico en 1888, y su padre, que se llamaba Bernardo Illanes Marcoleta, de abogado en 1861, ambos en la Universidad de Chile. Siempre dicen que Víctor Luis era muy generoso. Era doctor en Linares, y no cobraba por la consulta. La gente lo adoraba, y le pagaban con gallinas y cosas para comer. El amor y agradecimiento llegaba a tal punto, que justo antes de morir, el pueblo de Linares le regaló un auto, que posteriormente heredaría mi bisabuelo Pepe. La razón por la que Víctor Luis murió, fue que, a sus 68 años, acudió a visitar a un enfermo para tratar de ayudarlo, y éste lo contagió. Prueba de su importancia en la localidad, es que hoy una de las calles del centro de Linares lleva su nombre. He leído en un diario que el padre de Víctor Luis, Bernardo, era por el estilo en el lugar donde él vivía, Ovalle. Un artículo en el diario ovallense "El Tamaya", dice que cuando murió, todo el pueblo hizo un desfile por la calle principal, y hasta el cementerio. Mi bisabuela Olga tenía una buena vida, pero como su padre practicaba el oficio, más que por lucrar, por amor al arte, no tenían muchos bienes. Como mencioné, mucha de la comida que tenían era regalada, y la casa donde vivían, era arrendada. La única propiedad que ostentaban, fue una herencia por parte de la madre de mi bisabuela, Rosa Guerrero Valenzuela. Ella era de Santiago, pero sus padres eran de la zona de Colchagua y San Fernando. La madre de Rosa, Carlota Valenzuela Torrealba, pasó sus últimos días en una casa ubicada en la calle Marina de Gaete, cerca de Avenida Matta, en Santiago. Dicha propiedad estaría en la familia hasta los últimos años del siglo XX. Mi abuelo no conoció a su abuela Rosa Guerrero, pues falleció de 55 años, 6 años antes de que él naciera. De ella se sabe que era muy bonita. Es más, fue nombrada belleza de Chile por la Revista Zig-Zag, en la década de 1880. Ahí aparece su foto, donde se aprecia su rubio y rizado cabello, además de sus celestes ojos. Antes de casarse con Víctor Luis, Rosa vivió muchos años cerca de Curicó, junto a su padre, José Ramón Guerrero Campos. Cuando él se volvió a casar, se fueron a vivir a Santiago a una casa ubicada en la calle Lira, a una cuadra de la Alameda. Fue precisamente ahí que conoció a Víctor Luis, mientras éste estudiaba medicina. Al momento de 
titularse Víctor Luis, tenían ya dos años de casados, y un hijo. Según una tía abuela, algo que unía mucho a los abuelos maternos de mi abuelo, es que ambos tuvieron ausencia de madre en su vida. Víctor Luis, quedó huérfano de su mamá, Catalina Schedler Ortega, a los 6 años. Rosa, por su parte, no quedó huérfana joven, pero fue alejada de su progenitora. Esto sucedió, porque la familia de su madre se oponía a que se casara con su padre, pues implicaba la división de las tierras que ostentaban en la zona de San Fernando. Por esto, luego de que dio a luz, fue el padre el que se hizo cargo de ella. Lo más triste, es que a mi tatarabuela Rosa siempre se le dijo que su mamá había muerto, y recién supo que esto era mentira, cuando realmente falleció y le dejó todo en herencia en 1912, año en que Rosa tenía 51 años. Esto fue un hallazgo que pude lograr a través de mi investigación, y no desiste de dejarme perplejo lo conservadora y retrógrada que podía ser la gente. Es impresionante cómo eran capaces de romper vínculos y alejar familiares, con tal de ocultar cosas que los hicieran pasar vergüenza.

Mi bisabuela Olga vivió tanto, que contaba que cuando ella era chica, visitó Linares el presidente Germán Riesco, cuyo gobierno se llevó a cabo entre 1901 y 1906. Llegó en tren, y la llevaron a ella, junto a otras niñas, vestidas elegantemente y con flores, a recibir al mandatario. Era muy regalona de sus padres y hermanos, al ser la menor, aspecto del cual se acuerda mi mamá, que dice que su abuela Olga, era mucho menos activa y trabajadora, que su abuela Brunilda.

Volviendo a mi Tata, de su infancia en Linares se pueden rescatar varias cosas. En primer lugar, que era de muy mala conducta y desordenado. Se robaba las muestras médicas de mi bisabuelo y las vendía, le pegó un chute a un cura en su colegio y fue expulsado de él, cambió su bicicleta por un caballo sin permiso de nadie, y tenían que hacerle los trajes con dos pares de pantalones, pues siempre los rompía y desgastaba mucho. Luego, cuentan que iban a ver a parientes a unos fundos que tenían en Curanipe, en la costa, y pasaban por la casa de las denominadas "tías Barros", que eran viejas, gordas, y tenían bigote. El viaje desde Linares a Curanipe duraba dos días, y en la carreta incluso llevaban piano para entretenerse. También dicen mi mamá y abuela, que hablaba mucho de la localidad de San Fabián de Alico, pero desconozco la razón de ello.

Mi abuelo fue enviado a Santiago a terminar su enseñanza escolar, y estuvo en el Colegio San Ignacio, ubicado en la calle Alonso de Ovalle, y luego, en el Internado Nacional Barros Arana, 
lugar del cual se graduó. Cuenta mi abuela, que cuando el Tata volvía a Linares en las vacaciones o en el verano, su mamá lo consentía a más no dar. Le tenía frutas en conserva y mermeladas, y él, con el fin de que sus otros hermanos no se las comieran, escupía adentro de los frascos al frente de ellos. Fue ingeniería civil en la Universidad de Chile la carrera que mi abuelo decidió estudiar. Posteriormente se desempeñaría como docente de la asignatura de Ingeniería en Transportes en dicha facultad. En sus años universitarios vivió en una pensión, así como también, en la casa del hermano mayor de su mamá, ubicada en Avenida Irarrázaval.

Estando en la mitad de su carrera, conoce a mi abuela que estudiaba en la facultad contigua, arquitectura, y comienzan a pololear. El Tata se caracterizaba por ser grandioso, y cuenta mi abuela que trataba de regalarle chocolates caros, y llevarla a comer a lugares buenos, pero que por lo mismo, se iba quedando sin dinero, y la última semana del mes sólo iban a caminar por el Parque Forestal. Esta característica de ser más lanzado en temas de dinero perduró para siempre, y fue buen complemento para mi abuela, pues ella es totalmente lo contrario, y prefiere ahorrar y no gastar dinero a menos que sea sumamente necesario. Otra cosa que caracterizaba mucho a mi abuelo, es que era hincha del equipo de la Universidad de Chile. Estaba inscrito, y llevaba a mi abuela a ver los partidos, especialmente, el clásico universitario. Según ella, más que ver el fútbol, se asombraba de cómo la gente gritaba y cuánto fanatismo había. Para ella, que tenía puras hermanas y un padre que no veía fútbol, ésta era una experiencia completamente nueva. La descripción de mi abuelo no podría estar completa sin hablar de política. Si había otra cosa que lo caracterizaba, era que era una persona muy interesada y participativa en ella. Originalmente, mi abuelo militaba en el Partido Conservador. Por encontrarlo muy retrógrada, fue parte de la masa de jóvenes que decidieron salirse, y formar "La Falange", que luego se convertiría en la Democracia Cristiana. Por herencia de su abuelo Víctor Luis, mi Tata tenía una gran consciencia social y de clases. Seguía la doctrina del Humanismo Cristiano, y quería aminorar la gran brecha en cuanto a trato y calidad de vida, que había con la clase obrera. Prueba de su consciencia social, es que mi abuelo, cuando urbanizaba parte del barrio de Miraflores en Viña del Mar, regaló terrenos, en la zona de Miraflores Alto, a todos sus empleados, incluidas las nanas de la casa. Una de las calles de esa parte de viña, se llama José de la Fuente, nombre que eligió mi abuelo en honor a su padre. 
Lo triste es que desde joven que mi abuelo tuvo mala salud. Mientras estaba en la universidad, perdió un año entero a causa de un fuerte problema en el páncreas. Estos problemas de salud estarían ausentes por casi 40 años, hasta que mi abuelo pasó los 60 , y volvió a enfermarse constantemente. En todo caso, no se cuidaba mucho. Era una persona sumamente sociable, de buen genio y amante de la vida. Le encantaba hacer asados y comer carne y fumar, sobre todo puros. Cuando tenía cuarenta y algo años, el doctor le dijo que si no dejaba de fumar, iba a dejar huérfanos a sus hijos, y recién ahí se trató de poner en campaña para tener una vida más saludable.

\section{Pigua}

Creo que esta es la parte de la familia que más da para hablar. Son muchos los factores que contribuyen a ello, de los cuales destaco la abundancia de verdaderos personajes a nivel familiar, así como el contacto que he tenido con mi abuela. Es cierto que al momento de nacer tenía a mis cuatro abuelos vivos. Pero, a pesar de ello, la Pigua es la única con la que realmente he tenido una relación. Por mucho tiempo pensé que era muy desafortunado, ya que, como nací cuando mis papás ya eran mayores, sólo tuve la oportunidad de conocer a uno de mis cuatro antepasados de esta generación. No obstante ello, no puedo más que agradecer en este aspecto. La relación que tengo con mi abuela materna dista enormemente de lo convencional. Para mí ella es una segunda madre, alguien que es parte de mi vida periódica, que sabe de mis decisiones, y con quién he tenido la posibilidad de conversar de los más variados tópicos, ya sean morales, políticos o íntimos. Nuestro vínculo es potente, y creo profundamente que el cariño que ella me da llena y hasta rebalsa lo que cuatro abuelos juntos podrían entregarle a un nieto. La Pigua siempre ha sido mi ventana al pasado, mi conexión a las antiguas generaciones. Su departamento es un verdadero museo. Tiene en su living las pinturas hechas por su abuela paterna. Asimismo, hay álbumes que muestran fotos de la familia desde mediados del siglo XIX, como también, fotos antiguas y retratos colgados en las paredes. Soy sumamente afortunado de tener una abuela con tan buen estado de salud, pues a sus 87 años, la Pigua sigue yendo a clases de gimnasia con gente 30 años menor que ella, a clases de historia donde no deja de aprender cosas nuevas, y hasta hace poco, a clases de la Biblia. Su historia, y la de su familia, son muy bien conocidas por mí, lo que no quita 
que, tras largas investigaciones, vayamos aprendiendo cosas nuevas que no solían formar parte de nuestra memoria familiar.

Fue el 3 de noviembre de 1926 el día en que Nilda Alicia Roxana Santander García nació. A pesar de que su madre debió haber dado a luz en Constitución, pues allí residía la familia, decidió viajar a Santiago a tener a mi abuela en la casa de su suegra y la madre de ésta, ubicada en la calle José Miguel Carrera altura 200 algo, actualmente en pleno Barrio Universitario. La Pigua era la cuarta de la familia conformada por Ricardo Enrique Santander Godoy, y Brunilda Rosa García (Muñoz) López. El tema de la dualidad de apellidos entre Muñoz y García será tratado más adelante. Tras el parto, mi abuela volvió junto a su mamá a Constitución, donde pasaría los primeros cuatro años de su vida. Vivían primero en la denominada "casa de la playa", que se ubicaba en la costanera de la localidad, y atrás limitaba con un cerro. La casa era fiscal, pues mi bisabuelo dirigía las obras de la construcción del puerto de Constitución, y a la vez, hermosa, teniendo una característica balaustrada que aparece en diversas fotos. Los primeros recuerdos de mi abuela son caminando por la playa que se ubicaba frente a esta casa, así como también sentada en el escritorio de su padre mientras se sanaba una herida que tenía. Me dice que en esos días, mientras se curaba en aquel cuarto, aprendió a escribir su nombre. Después se cambiaron a la “casa de la plaza”, ubicada en plena Plaza de Armas, que tenía una escalera que descendía al patio. Durante los años que residieron en Constitución, mis familiares vivieron el terremoto de Talca de diciembre de 1928. Según mi bisabuelo, que escribió un libro sobre su vida, debieron vivir en una carpa por meses, mientras se arreglaban las edificaciones. Tras fracasar la construcción del puerto de Constitución, mi bisabuelo, junto a su señora e hijas, migraron a Santiago. Ahí, residieron en Tocornal (actual Eduardo Castillo Velasco) 3280, en la comuna de Ñunoa. Ese fue el hogar de mi abuela hasta finales de 1932. Se acuerda que había una gran palmera, y que vivía con su abuela paterna, la "mami Zoila". La vida le parecía sonreír a los Santander, que hasta ese entonces tenían 4 hijos: Ricardo, Eliana, Ximena y mi abuela, Nilda. Sin embargo, como la vida da abruptas vueltas, una inusitada tragedia los golpeó. El 10 de diciembre de 1932, durante el show de la premiación de fin de año del English Institute, Ricardo, el hermano mayor de mi abuela, se soltó de sus compañeros mientras presentaban, tropezó y se pegó en la cabeza contra el concreto. La familia completa presenciaba el acto, y por más que se 
quisiera, no había nada que hacer. Ricardito, que aún estaba a 10 días de cumplir los 10 años, falleció. Según mi abuela que su padre se descompuso, y fue su madre quién debió ser fuerte y salir adelante con la familia. En sus memorias, mi bisabuelo escribió que el mismo día de su muerte, su hijo lo había saludado al desayuno con dos besos, en vez de uno. “¿Cómo no me di cuenta que se estaba despidiendo?" escribió. Esta impotencia lo acompañó el resto de sus días, pero afortunadamente, aunque la pena fue permanente, logró sobrellevar la situación y ser feliz. Ni bien ocurrió esto, mi bisabuelo Ricardo decidió huir de la capital. Llevó a su familia a la quinta de sus suegros en Temuco, y pasaron allí el verano completo, hasta fines de marzo. El "tata Isaías" y la "mami Cleme", como mi abuela conocía a sus abuelos maternos, les brindaron todo el apoyo necesario. Le sugirieron a mi bisabuelo que se quedase en la Araucanía, que tratara de entablar una nueva vida allí. Él no quiso, pues amaba las urbes, y creía que vivir fuera de Santiago, Valparaíso o Concepción, sería muy pueblerino. Finalmente, mi bisabuelo compró un terreno en el Cerro Castillo en Viña del Mar, y comenzó a construir una casa que sería de su propiedad hasta poco antes de su muerte. La casa de Iberia 390, como se conoce en la familia, demoró un tiempo en estar lista, por lo que en el intertanto vivieron en una propiedad en la calle Von Schroeders en pleno centro de Viña. Mientras estuvieron ahí ocurrieron dos cosas importantes. En primer lugar, llegó a este mundo Gloria, la hermana menor, que había nacido casi un año después de que Ricardito muriera, en octubre de 1933. Y en segundo, falleció la única bisabuela que mi abuela conoció, Rosa Herrera Fuenzalida, el 9 de noviembre de 1933. Esta bisabuela era la madre de la abuela paterna de mi abuela. Vivió 93 años, y la Pigua sólo se acuerda de haberla ido a ver un par de veces a la casa de su hijo, el medio hermano de la abuela de mi abuela, en la Avenida Chile-España en Ñuñoa. La casa de la calle Iberia estuvo lista en 1936. En este periodo, mi abuela y sus hermanas iban al Giffen School for Girls, colegio inglés que funcionaba bajo los parámetros británicos. Mi bisabuelo, por su parte, trabajaba toda la semana en el puerto de Talcahuano, volviendo los fines de semana a Viña para estar con su familia. Y, finalmente, mi bisabuela Brunilda hacía los trámites legales para rectificar su partida de nacimiento, con el fin de esconder algo que nos sería ajeno hasta mediados del año pasado, y que sólo pudo ser clarificado gracias a las sospechas de mi abuela y a mi labor investigando en distintos registros y archivos. Mi bisabuela nació como Brunilda Rosa García, el 28 de febrero de 1892, en San Javier. Su padre biológico era José Manuel García Evans, quien descendía de 
familias fundadoras de la zona de San Javier y Villa Alegre, y por parte materna, del irlandés John Evans, quien había llegado a las costas de la zona de Ñuble a mediados del siglo XVIII, y había castellanizado su nombre a Juan Ibáñez. Brunilda siempre fue conocida con el apellido Muñoz, y esto se debía a que su padrastro, el marido de su madre quien ostentaba ese apellido, la adoptó. La madre de mi bisabuela, Clementina López Troncoso, era también de San Javier, y tras tener a su hija, conoció a Isaías Muñoz Márquez y se fueron a vivir a Santiago, y luego a Valparaíso. Debido a los prejuicios sociales que conllevaba esto, mi bisabuela nunca contó sobre su pasado. Su historia partía en Valparaíso, cuando su madre y padrastro ya estaban asentados, y habían formado su familia. Mi abuela me cuenta que vivían cerca de la Plaza Echaurren en la parte antigua del puerto de Valparaíso, y que luego, cuando se estaba fomentando la colonización en la zona conocida como "La Frontera", es decir, Temuco y la Araucanía, el Tata Isaías creyó que sería una gran oportunidad, y partieron allá. Isaías y Clementina tuvieron muchos hijos, y los dos menores nacieron en Temuco dos décadas después de que naciera mi bisabuela Brunilda. Allá vivieron en una casa cerca de la plaza, donde se casaron mis bisabuelos, y luego adquirieron la quinta de la que hablé anteriormente. Mi abuela se acuerda de los veranos que pasaba allá. Dice que estaban tres meses, que sus abuelos las regaloneaban mucho, y que incluso, cortaban un pino para ponerlo como árbol de Navidad cuando nadie hacía eso. Esta costumbre era más popular en esta zona, debido a la considerable cantidad de colonos alemanes que existía. Mi abuela dice que su mamá tenía muy buen gusto por naturaleza, y que era sumamente activa. Brunilda ayudaba con cosas de carpintería, cocinaba y dirigía a maestros y empleados si era necesario. No era una persona regalona, sino que al contrario, era de cierta manera quien llevaba el ritmo de la casa. Por el otro lado, el papá de mi abuela era una persona a la que le gustaba ser regaloneada. Dice la Pigua que su infancia fue muy solitaria, puesto que no tuvo hermanos, y le tocó vivir siempre con su madre y abuela materna, siendo esta última una figura particularmente absorbente. La historia de mi bisabuelo Ricardo también nos lleva a Valparaíso. Él nació en los primeros días de marzo de 1894, y era el primer hijo de Ricardo Santander Gómez y Zoila Godoy Herrera. El papá de mi bisabuelo era Contador Mayor de la Armada, y había viajado a bordo de la corveta Abtao. La mamá de mi bisabuelo era quince años menor que su marido, y venía de Chañaral. Era alta, flaca, de tez muy blanca y de ojos celestes profundos. Según la Pigua, que su abuela fue educada para ser princesa, pero no le tocó vivir esa vida, pues enviudó muy joven, y 
debió hacerse cargo de su hijo. La mami Zoila hablaba francés e italiano, era soprano y concertista de piano, pintaba y sabía todos los protocolos habidos y por haber. Mi abuela, de sus abuelos paternos, sólo la conoció a ella. Vivieron varios años juntas, y se acuerda que jugaban naipes, que las llevaba por el centro de Viña a caminar y a tomar helado, y que contaba chistes. No le gustaba salir con todas sus nietas a la vez, pues se portaban muy mal. Pero lo bueno de esto, es que cuando le tocaba salir con la mami Zoila, las conversaciones eran mucho más profundas. Ella enseñaba catequesis, y siempre estuvo de luto, desde que perdió a su marido cuando tenía 33 años. Mi bisabuelo estudió ingeniería porque su papá, antes de morir, le dijo que esa sería la carrera del siglo XX en que a él le tocaría vivir. Escuchando a su padre, y sin mucho amor por la carrera, decidió estudiarla. Me cuenta mi abuela que a pesar de decir que encontraba terrible estudiar ingeniería, su oficio le trajo varias cosas buenas, y que de hecho, logró disfrutarlo sobre todo cuando tuvo que ayudar a construir varios puertos en Chile, gracias a su cargo en el Ministerio de Obras Públicas. Fueron diversos los viajes que mi bisabuelo hizo por ostentar este oficio, como por ejemplo a Estados Unidos al mismo tiempo que probaban la Bomba Atómica, y a Inglaterra al año siguiente de que había terminado la Segunda Guerra Mundial. Él era asimismo políglota. Amaba los idiomas, y tenía facilidad para ello. Cuando era pequeño, había aprendido francés gracias a su madre y por exigencias de su colegio. Luego aprendió el inglés, y tomó diversos cursos de otras lenguas, como alemán, sueco, italiano, etc. Es interesante que aprendiera a hablar ruso, puesto que en plena Guerra Fría, viajó con mi bisabuela a la Unión Soviética. Era además muy adelantado para su época. En primer lugar, no quería que sus hijas lo trataran de usted, y las dejaba tutearlo. Evidentemente que el mismo trato corría para mi bisabuela. Además, mi abuela me contó que incluso a sus abuelos los trataba de tú. Era verdaderamente un hombre visionario, pues aun mi mamá, que es una generación menor, trataba a sus abuelos de usted. También, mi bisabuelo quería que sus hijas estudiasen, y no tenía prejuicios contra homosexuales.

Cuando volvieron a Santiago en 1938, la Pigua vivió en varios departamentos en el actual sector de Bellavista. El que fue su residencia por más tiempo, está ubicado en la esquina de Avenida Santa María con Patronato. Hasta el día de hoy existe, y mi abuela me cuenta que en aquella época, la calle Patronato se llamaba Vásquez. En esos años, fue estrenada en Chile la película 
"Lo que el viento se llevó". Era para mayores de 13, y mi abuela se moría de ganas de verla. Por lo mismo, se pintó y puso tacos para verse mayor, y logró entrar.

Con la idea de que sus hijas fuesen profesionales, mi bisabuelo decidió que ellas estudiaran en el Liceo 1. Mi abuela tiene muy buenos recuerdos de su colegio, diciendo que era de excelencia. En 1943 finalmente se graduó, dio el bachillerato, y al año siguiente, ingresó a la carrera de arquitectura en la Universidad de Chile, que se encontraba junto a la actual facultad de Ingeniería, en Beauchef. Fue ahí cuando conoció a mi abuelo, pues él estudiaba ingeniería, y comenzaron sus cuatro años de pololeo. La Pigua era una mujer muy atractiva, y prueba de ello es que no le faltaban pretendientes. Comenzó a pololear a los 15 años, y tuvo tres pololos antes de mi Tata. Recuerdos de esta época son que se iba en tranvía a la escuela de arquitectura, que caminaba con el Tata por el Parque Forestal, y que él le compraba chocolates de la famosa Varsovienne. En segundo año, mi abuela decidió salirse de arquitectura, y tomó unos cursos de francés, dentro de los cuales fue alumna destacada. Unos años después, mi abuelo le pidió matrimonio. Se casaron en junio de 1948, en una pequeña capilla ubicada en la calle Mac Iver. 


\section{Bibliografía}

Berel Wein and Destiny Foundation. (2007). Faith and Fate: Jewish History (1900-1910). Documental.

Don Bernardo Víctor Illanes. (1896, 20 de julio). Diario El Tamaya de Ovalle, p. 7.

Dubnow, Simon. (2000). History of the Jews in Russia and Poland. Estados Unidos: Avotaynu Editions.

Figes, Orlando. (2008). La Revolución Rusa (1891-1924): la tragedia de un pueblo. España: Editorial Edhasa.

Gitelman, Zvi. (1988). A century of ambivalence: The Jews of Russia and the Soviet Union, 1881 to the present. Estados Unidos: Indiana University Press.

Hanish, Babette. (1995). Our story: Mother and daughter, an intergenerational heritage, continuity and connectedness. Tesis de magíster no publicada. San Francisco State University, San Francisco, Estados Unidos.

Pino Zapata, Eduardo. (1969). Historia de Teтисо. Temuco: Ediciones Universitarias de La Frontera.

Salazar, Gabriel. (2006). Ser niño "huacho" en la historia de Chile. Santiago de Chile: LOM Ediciones.

Santander Godoy, Ricardo. (1979). Mi vida. Manuscrito no publicado.

Schwaab, Ronya. (1994). My reminiscences. Manuscrito no publicado.

Villalobos R., Sergio. (1974). Historia de Chile. Tomo 4. Chile: Editorial Universitaria.

Wolfman, Ira. (2003). Jewish New York. Nueva York: Universe Publishing. 


\section{Anexo: Fotos y documentos}
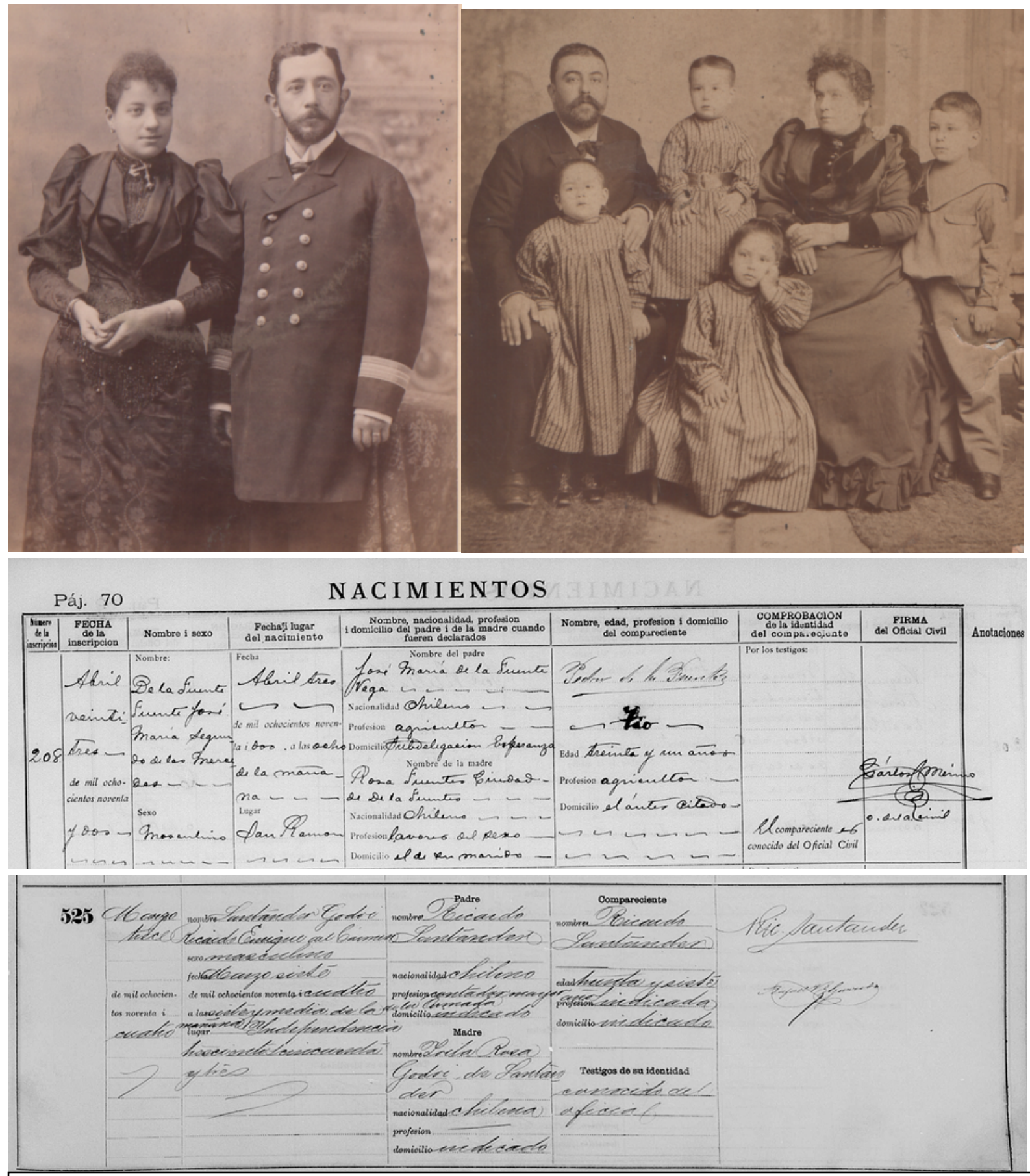

1. Mis tatarabuelos Ricardo Santander Gómez y Zoila Godoy Herrera (Valparaíso, 1893),

Familia Illanes Guerrero (Linares, 1895), 3. Certificado de nacimiento de mi bisabuelo José María de la Fuente de la Fuente (1892), 4. Certificado de nacimiento de mi bisabuelo Ricardo Santander Godoy (1894). 

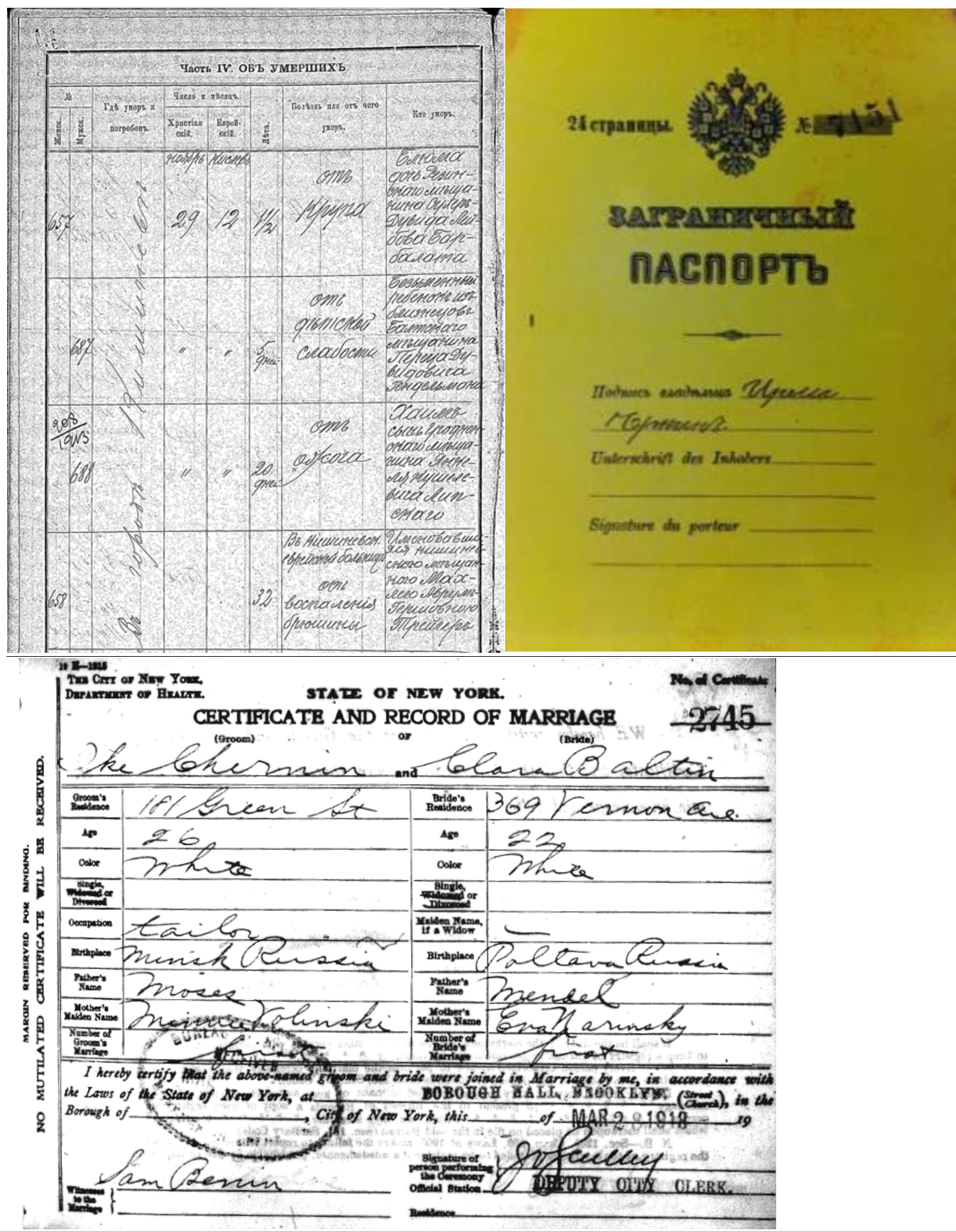

1. Certificado de defunción de mi tatarabuela Machla Wasserman Cohen (1902), 2. Pasaporte ruso de mi bisabuelo Anshel Chernin Volinsky (1912), 3. Certificado de matrimonio de mis bisabuelos Anshel (Ike) Chernin Volinsky y Chava (Clara) Bolotin Narinskv (1918). 

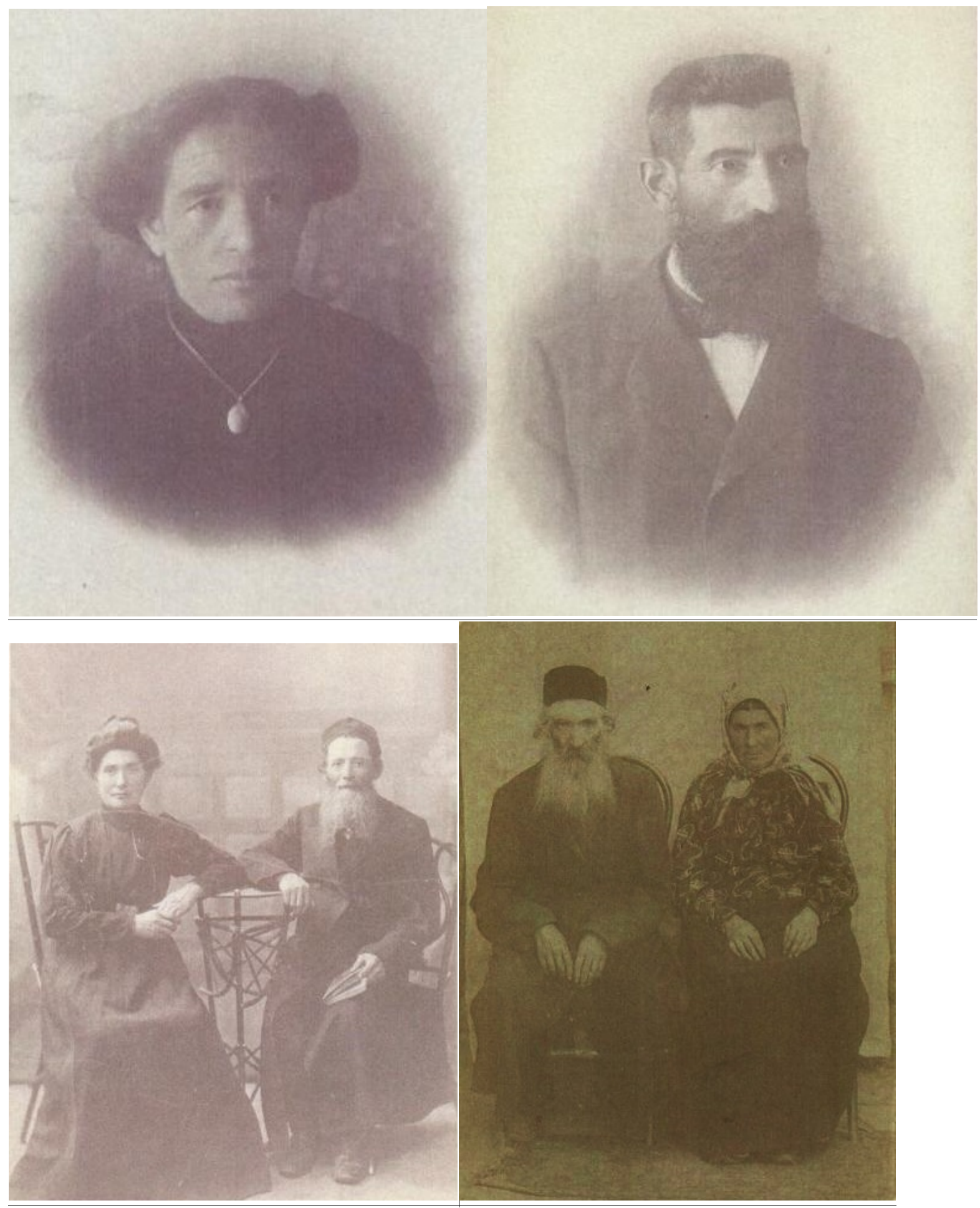

En el sentido del reloj: 1. Mi tatarabuela Michla Volinsky, 2. Mi tatarabuelo Moshe Chernin, 3. Los padres de Moshe Chernin, 4. Los padres de Michla Volinsky. Las cuatro fotos fueron tomadas en Bielorrusia. 

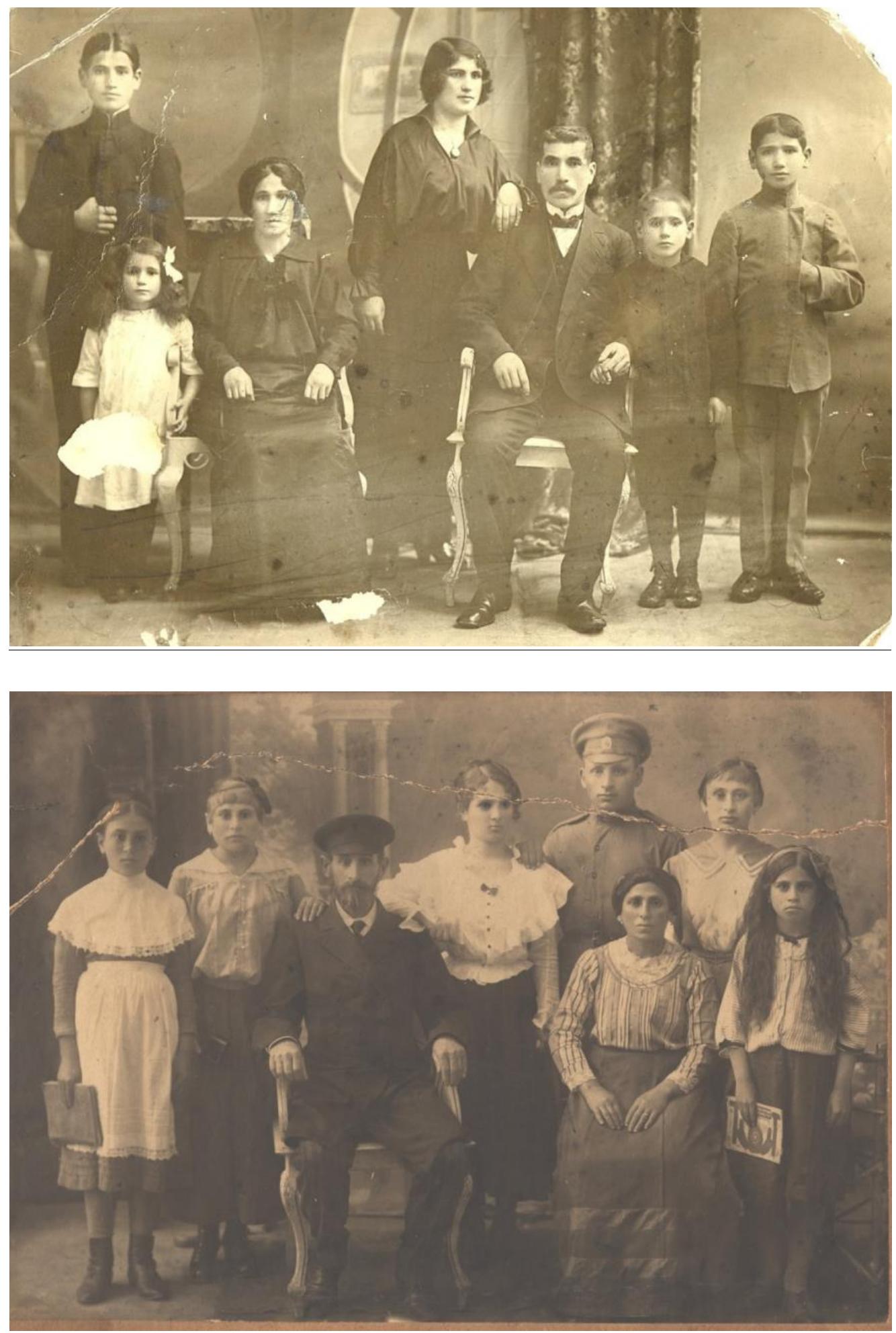

1. Familia Fuchsman Grosskopf (c. 1907), 2. Familia Treger Wasserman y Treger Kiskaman. Aparece la segunda esposa de mi tatarabuelo Moshe (1913). Ambas fotos tomadas en Kishinev. 